\title{
ACUPUNT URA NO CUIDADO DE ENFERMAGEM AO PACIENTE COM CISTO PILONIDAL: um relato de experiência assistencial
}

\author{
M ateus Casanova dos SANT OS
}

\begin{abstract}
RESUMO
0 presente estudo de caso assistencial, com caráter qualitativo, descritivo e participante, denota o uso da acupuntura no tratamento complementar de um paciente em acompanhamento médico e de enfermagem, possuindo cisto pilonidal sacrococcígeo recidivo com complicação infecciosa nos tecidos circunjacentes. Tem como objetivo identificar esse suporte em saúde complementar como uma estr atégia potencial de utilização nos cuidados de enfer magem implementados aos pacientes. Observou-se que a acupuntura e 0 acompanhamento multiprofissional beneficiaram a recuper ação tecidual local, o combate à infecção, contribuindo sobremaneira, ao fazer a consulta de enfermagem, para o enfrentamento positivo da enfermidade e a melhor adesão do paciente às orientações dos cuidados de enfermagem. De imediato, observa-se a necessidade de maiores estudos e aprofundamentos científicos sobre as contribuições das práticas orientais em saúde na enfer magem.
\end{abstract}

D escritores: Seio pilonidal. Cuidados de enfermagem. A cupuntura.

\section{RESUMEN}

E ste estudio de caso asistencial, de carácter cual itativo, descriptivo y participante, denota el uso de la acupuntura como complemento del tratamiento de un paciente en acompañamiento médico y de enfermería, tras sufrir la enfermedad pilonidal sacrococcigea con recaídas y complicaciones infecciosas en los tejidos circundantes. T iene como objetivo identificar ese sopor te en la salud complementar como una estrategia potencial para su uso en la atención de enfermería aplicada a los pacientes. Se observó que la acupuntura y el seguimiento multiprofesional beneficiaron la recuperación del tejido local, la lucha contra la infección y contribuyeron, en gran medida, al hacer la consulta de enfermería, deforma positiva para enfrentar la enfer medad y mejorar la adhesión del paciente con las directrices deatención de enfer mería. I nmediatamente, se observó que hay una necesidad de estudios nuevos y de mayor profundiz ación en los estudios científicos sobre las contribuciones de las prácticas de la salud oriental en la enfermería.

Descriptores: Seno pilonidal. A tención de enfermería. A cupuntura.

Título: A cupuntura en cuidados de enfermería al paciente com quiste pilonidal: un relato de experiencia de atención.

\section{ABST RACT}

This qualitative, participant and descriptive assistance case study shows the use of acupuncture in the complementary treatment of a patient with sacroccocygeal pilonidal cyst relapse with infectious complications in the sur rounding tissues receiving medical and nursing assi stance $T$ he pur pose is to identify this support in complementary health as a potential strateg y to be used in thenursing care offered to the patients. It was observed that acupuncture and the multiprofessional assistance benefitted the recovery of local tissue and the combat of infection. By the time of the nursing appointment, these techniques greatly contributed for the positive combat of the disease and a better adhesion to the orientations of nursing care practitioners. F urther studies and scientific research about the contributions of or iental health practices in nursing are necessary.

D escriptors: Pilonidal sinus. N ursing care Acupuncture

$T$ itle: A cupuncture in the nursing care of a patient with pilonidal cyst: an assistance experience report.

a Especialista em Saúde Coletiva e em A cupuntura e El letroacupuntura, M estrando do Programa de Pós-Graduação em E nfermagem da U niversidade Federal de Pelotas (U F Pel), E nfermeiro D ocente da Faculdade A nhanguera Educacional Pelotas, Rio G rande do Sul, Brasil. 


\section{CONSIDERAÇÕES INICIAIS}

0 artigo apresentado é um relato de experiência assistencial em enfer magem com a utilização da acupuntura como ter apia complementar nos cuidados de saúde de um paciente com cisto pilonidal recidivo e infectado. 0 estudo tem como objetivo identificar a acupuntura como uma estratégia potencial de utilização nos cuidados de enfermagem implementados aos pacientes, tendo em vista a necessidade do aprimoramento da enfermagem na regulamentação legal desta atividade ${ }^{(1)}$.

A acupuntura baseia-se na filosofia taoísta, datando a origem há cerca de 1500 antes de Cristo (a.C.). N esta teoria, a inter ação dinâmica que as pessoas têm com seu próprio desenvolvimento, saúde e bem-estar é influenciada pelo meio ambiente ao redor ${ }^{(2,3)}$. Há duas expressões polares clássicas para caracterizar este estado salutogênico: "O $Y$ in é uniforme e forte, enquanto o Y ang é firme, então a saúde está garantida", ou ainda, "O Y in e o Y ang estão em harmonia, a saúde está preservada"(3). 0 Q i como força natural da vida, referente ao que se conhece como energia que permeia a vida, podendo se expressar como energia espiritual, emocional, física e através dos processos mentais, percorre as estruturas orgânicas e viscerais corporais (Zang $\mathrm{Fu}$ ), tanto em âmbito superficial como profundo ${ }^{(2-4)}$. N os locais do corpo humano onde os meridianos percorrem há alta condutividade de potencial elétrico e denominam-se pontos de acupuntura. N estas localizações o Qi transita carreado de informações neuroquímicas específicas e com alto poder de auto-organização quando devidamente acionado em um circuito terapêutico(3-6).

\section{CAMINHOS METODOLÓGICOS PERCORRIDOS}

0 relato é um estudo de caso com caráter qualitativo, descritivo e participante ${ }^{(7)}$ e se integra ao projeto intitulado "Resgatando a integralidade holística nas práticas de cuidado complementar em saúde", aprovado no Comitê de É tica em Pesquisa da Faculdade de M edicina da U niver sidade Federal de Pelotas, Ofício 009/05. 0 estudo de caso, observando a Resolução 196/96(8), foi realizado entre os meses de abril, maio e junho de 2009 no município de Pelotas, Rio G rande do Sul, utilizando como base um serviço de atendimento em práticas complementares em saúde.

\section{O EST UDO DE CASO}

O paciente denominado pelas siglas M .H.B., 38 anos, solteiro, masculino, brasileiro, agricultor, estatura: 1,85 metros, massa corporal: 83000 gramas, procurou o serviço de enfermagem em 15.04.2009 solicitando cuidados com uma lesão recidiva sobre a linha interglútea (F igura 1 ). A o exame clínico, o paciente apresentava-se em $\mathrm{G}$ lasgow 15; deambulando sem auxílio, mas com dificuldade de flexão do tronco durante a marcha; tensão arterial em membro superior direito sistólica 120 (milímetros demercúrio) mmH g e diastólica $80 \mathrm{mmH} \mathrm{g;}$ pulso radial em 72 batimentos por minuto, aspecto cheio, regular, superficial e vasto (hong)(3), caracterizando excesso de calor patogênico(3); $\operatorname{cog}$ nição e fala preservadas; tez avermel hada, mucosa oral de cor rosácea e íntegra; língua pontuda, vermel ha na ponta e saburra fina de coloração hialina; eupnéico; normocárdico; eutérmico; diurese continente, espontânea; el iminações intestinais estáveis; atividade sexual semanal; membros inferiores com adequada integridade dos fâneros e edemas ausentes. N o dorso havia a lesão sacrococcígea com secreção purulenta, aberta e apresentando dor inflamatória local, com dificuldade para manter atividades da vida diária, como vestir-se, realizar caminhadas e trabal har no labor rural. A ssim, identificou-se como diagnósticos de enfer magem, baseando-se na teoria das $\mathrm{N}$ ecessidades $\mathrm{H}$ umanas ena $\mathrm{N}$ or th $\mathrm{A}$ merican $\mathrm{N}$ ursing D iagnosis A ssociation ${ }^{(9)}$ : manutenção da saúde alterada, interação social comprometida, integridade cutânea prejudicada, risco para infecção, medo, ansiedade, dor, desesper ança, baixa auto-estima situacional e potencial déficit de autocuidado. As orientações médicas caracterizaram a lesão como um cisto pilonidal ${ }^{(10)}$, havendo a necessidade de manter os curativos diários. A conduta médica baseou-se em antibioticoterapia oral, acompanhamento proctológico e de enfermagem.

0 cisto pilonidal é um resquício embrionário da pel e que, normalmente, contém em seu interior pêlos e tecido glandular ${ }^{(10)}$.

No dia 20.04.2009, o paciente começou a realizar os curativos diários oclusivos e estéreis no consultório de enfermagem. Para limpeza da lesão utilizou-se soro fisiológico a $0.9 \%$ com temperatura 38 graus centígrados e instilação desta solução nas fístulas para remoção das secreções purulentas. 


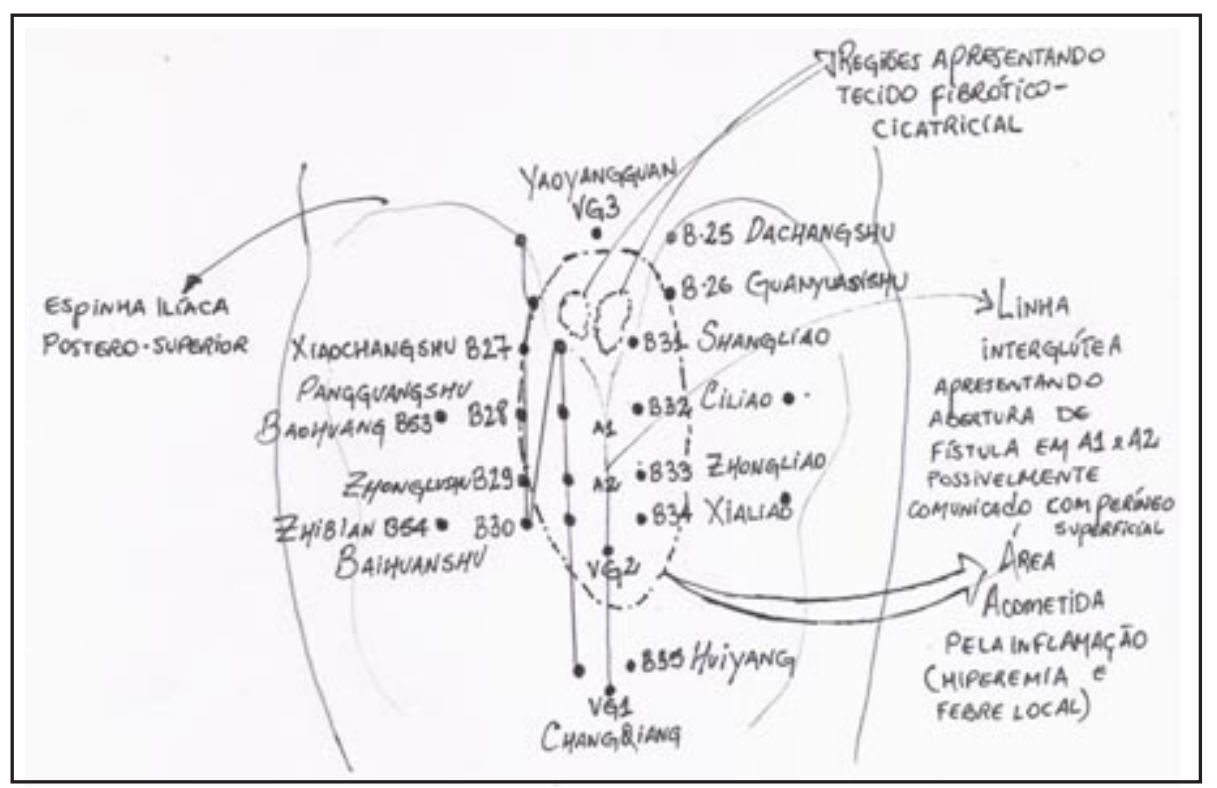

Figura 1 - Desenho anatômico representando a região sacrococcígea do paciente.

Durante os primeiros atendimentos, definiuse o diagnóstico oriental clássico ${ }^{(3,11)}$, complementando os diagnósticos médico e de enfermagem. Segundo os oito princípios: calor, cheio, interior, Yang; segundo os seis excessos: calor cheio e umidade; fleuma-calor no aquecedor inferior; diagnóstico sindrômico misto: deficiência do Yang do BaçoPâncreas e Rim em fase inicial(11).

N este caso, teve-se como base do raciocínio ter apêutico o uso eficaz da acupuntura sistêmica(11), apoiando-se de imediato ao combate à infecção tecidual através da tonificação do Qi defensivo e do Qi nutritivo, assim como expulsão do calor-umidade. Durante o tratamento, tonificou-se os acoplados Baço-Pâncreas e Rim e promoveu-se a regulação e estimulação nos canais da Bexiga e do Vaso G overnador, dos pontos de alarme eqüidistantes à lesão e dos pontos de influência dos ossos, cartilagem, sangue, vasos sanguíneos, músculos e tendões ${ }^{(2,3,11)}$.

A partir do dia 20.04.2009, o acompanhamento ocorreu em vinte consul tas de enfermagem, onde as treze primeiras foram diárias, as cinco seguintes foram intercaladas com intervalo de um dia, e as outras duas últimas foram intercaladas com interval os de quatro dias, sendo a última consulta da série no dia 17.05.2009.

0 paciente evoluiu melhorando significativamente a dor inflamatória local a partir do terceiro encontro em 40\% (22.04.2009), a mobilização do quadril durante a marcha a partir do sexto atendimento (25.03.2009), diminuindo a hiperemia e se- creção purulenta local a partir do décimo segundo atendimento (01.05.2009) e, inclusive, atenuando as condições psíquicas de medo e ansiedade e apresentando resposta positiva para a aceitação do enfrentamento da enfermidade, da retomada da interação social e da preservação da auto-imagem. Os níveis pressóricos da tensão arterial periférica do paciente mantiveram-se estáveis durante os atendimentos.

\section{CONSIDERAÇÕES FINAIS}

A o final dos 20 atendimentos, percebeu-se os benefícios da acupuntura com relação à diminuição da dor durante a manipulação da lesão, na estimulação angiogênica e do tecido de granulação da ferida, na resposta cicatricial constante observada diariamente a cada troca de cur ativo e os efeitos anti-inflamatórios e anal gésicos pertinentes à acupuntura ${ }^{(12)}$. A o final do atendimento, a lesão ulcerada de quatro centímetros de comprimento na linha interglútea havia cicatrizado e fechado, as fístulas não apresentavam drenagem de secreções e o tecido cicatricial estava com aspecto normocorado, em fase de mel hora e recuper ação. Concluiu-se que a rotina diária de troca dos curativos otimiza a utilização da acupuntura de forma rítmica, contribuindo com a eficácia no tratamento e na recuperação.

Com este estudo não se pôde concluir o quanto ou como a acupuntura contribuiu para o combate à infecção local, pois o paciente estava concomitante em uso de antibioticoterapia conforme a prescri- 
ção médica. A resposta anal gésica ea melhora para 0 enfrentamento da enfermidade eram imediatas na troca dos curativos, relatado pelo paciente.

E nfim, considerou-se também que o acompanhamento multiprofissional ${ }^{(13)}$, neste caso, entre os médicos e o enfermeiro, contribuiu no tratamento da enfermidade de forma aberta e isenta de preconceitos a novas possibilidades complementares em saúde ${ }^{(14)}$. 0 cuidado de enfermagem inovador na prevenção e no tratamento das feridas abertas infectadas e na dor inflamatória aguda e crônica, com o complemento da acupuntura como terapia não farmacológica, emergiu como uma potencial modalidade para a assistência de enfer magem, necessitando mais estudos de aprofundamento da acupuntura, sobretudo, junto aos diagnósticos de enfer magem, às trocas de curativo de ferimentos e, inclusive, para o risco de infecção percutânea durante a inserção e a manutenção das agulhas.

\section{REFERÊNCIAS}

1 Kurebayashi LF S, Oguisso T, F reitas G F. A cupuntura na enfer magem brasileira: dimensão ético-legal. Acta Paul Enferm. 2009;22(2):210-2.

2 H su DT. Acupuncture. Reg Anest. 1996;21:361-70.

3 Auteroche $B, N$ availh P. 0 diagnóstico na medicina chinesa. São Paulo: Andrei; 1992.

4 Leake R, Broderick JE. T reatment efficacy of acupuncture: a review of the research literature. Integrat M ed. 1998;1(3):107-15.

5 W ang $Y$, Zhang $Y, W$ ang $W, C$ ao $Y, H$ an J. Effects of synchronous or asynchronous el etroacupuncture stimulation with low versus high frequency on spinal opioid release and tail flick nociception. Exp N euro. 2005;192:156-62.
6 Saku K, M ukaino Y, Y ing H, Arakawa K. Characteristics of reactive electroper meable points on the auricles of coronary heart disease patients. Clin Cardiology. 1993;16:415-9.

7 Bogdan RC, Biklen SK. Investigação qualitativa em educação. Porto: Porto; 1994.

8 M inistério da Saúde (BR), Conselho Nacional de Saúde, Comitê $\mathrm{N}$ acional de Ética em Pesquisa em Seres Humanos. Resolução 196, de 10 de outubro de 1996: diretrizes e normas regulamentadoras de pesquisa envolvendo seres humanos. Brasília (DF); 1996.

9 Benedet AS, Bub M AC. M anual de diagnóstico de enfermagem: uma abordagem baseada na teoria das necessidades humanas básicas e na classificação diagnóstica da NANDA. Florianópolis: Bernúncia; 2001.

10 Borges $G$, M aciel JJA, Carelli EF, Alvarenga M, Castro R, Bonilha L. Pilonidal cyst on the vault: case report. Arq N euro-Psiq. 1999;57(2):273-6.

11 M aciocia G. Os fundamentos da M edicina Chinesa: um texto abrangente para acupunturistas e fitoterapeutas. São Paulo: Roca; 1996.

12 Yaksh TL, Hammond DL. Peripheral and central substrates involved in the Rostrad transmission of nociceptive information. Pain. 1982;13(1):1-85.

13 Ferreira SR, Olschowsky A. Residência integrada em saúde: a interação entre as diferentes áreas de conhecimento. Rev G aúcha E nferm. 2009;30(1):10612.

14 Santos M C, Siqueira H CH , Silva J RC. Saúde coletiva na perspectiva ecossistêmica: uma possibilidade de ações do enfermeiro. Rev G aúcha Enferm;30(4): 750-4.

Recebido em: 24/ 08/ 2009

A provado em: 24/ 02/ 2010

\author{
Endereço do autor / Dirección del autor / \\ Author's address: \\ $M$ ateus Casanova dos Santos \\ Rua D r. Ferreira Soares, 244 \\ 96020-160, Pelotas, RS \\ E-mail: mateuscasanova@ig.com.br
}

